\title{
Proses Adaptasi Kaum Muda yang Bermigrasi ke Kota Yogyakarta dan Bandung
}

\author{
Atika Dwi Aryand, Oki Mardiawan, FA Nurdiyanto \\ Center for Indigenous and Cultural Psychology, Fakultas Psikologi, Universitas Gadjah Mada, \\ Yogyakarta
}

Abstrak. Yogyakarta dan Bandung merupakan kota favorit untuk menempuh pendidikan. Ketika bermigrasi, kaum muda akan menghadapi proses adaptasi dengan lingkungan baru. Kegagalan saat beradaptasi dengan lingkungan baru akan memicu masalah psikologis seperti stres, cemas, dan gegar budaya (culture shock). Oleh karena itu, penelitian ini dilakukan untuk mengeksplorasi pengalaman kaum muda dalam beradaptasi selama bermigrasi ke kota Yogyakarta dan Bandung. Penelitian ini dilakukan dengan melibatkan 200 mahasiswa di Yogyakarta dan Bandung. Diskusi Kelompok Terarah (DKT) dilakukan dengan menggunakan analisis data tematik. Hasil penelitian menunjukkan bahwa, ketika kaum muda bermigrasi dan melakukan proses adaptasi, mereka cenderung mencari informasi, berinteraksi, dan menyesuaikan diri. Terdapat juga faktor predisposisi yang memengaruhi proses adaptasi kaum muda selama bermigrasi, yaitu faktor penghambat dan faktor pendukung selama beradaptasi. Penelitian ini memberikan sumbangsih terhadap perkembangan ilmu psikologi mengenai proses adaptasi dan faktor predisposisi pada kaum muda yang bermigrasi ke kota Yogyakarta dan Bandung. Penelitian ini juga diharapkan dapat memberikan pengetahuan kepada kaum muda yang memiliki pengalaman pertama melakukan migrasi ke kota besar.

Kata Kunci: kaum muda, migrasi, proses adaptasi

\section{Adaptation Process among Youths' Migration to Yogyakarta and Bandung Cities}

Abstract. Yogyakarta and Bandung as best favorite cities for education. When migrating, youth will face the process of adaptation to the new environment. The failure when adapting to the new environment will trigger psychological problems such as stress, anxiety, and fear (culture shock). Therefore, this study try to explore the experience of youth adapting during migration to the cities of Yogyakarta and Bandung. The study was involved 200 students in Yogyakarta and Bandung. Focus Group Discussions (FGD) are conducted by using thematic data analysis. The results show that young people migrate through the process of adaptation by finding information, interacting, and adjusting. On the other side, There also a predisposition factors influenced youth adaptation process during migration, namely inhibiting and supporting factors during adaptation. Therefore, This research might have contribution to the development of psychology science regarding the process of adaptation and youth predisposition factors who migrate to the cities of Yogyakarta and Bandung. Hopefully, the research would highly provide knowledge to young people with first experience migrating to big cities.

Keywords: adaptation process, migration, youth

Korespondensi: Atika Dwi Aryand. Email: atika.d.a@mailugm.ac.id 
Pembangunan di Indonesia selama ini masih terfokus di pulau Jawa. Hal ini berdampak pada ketidakmerataan fasilitas pendidikan, kemajuan ekonomi, dan industri yang mendorong kaum muda untuk bermigrasi ke kota besar. Malamassam (2016) menemukan ketimpangan fasilitas pendidikan dan kesempatan kerja telah mendorong sebagian besar kaum muda untuk bermigrasi. Menurut laporan Kemenristekdikti (2018), Yogyakarta dan Bandung merupakan daerah tujuan migrasi untuk menempuh pendidikan tinggi. Kedua kota ini memiliki sejumlah perguruan tinggi dan kondisi perkotaan yang mendukung pendidikan.

Yogyakarta terkenal sebagai kota pendidikan dan pusat budaya Jawa (Jong \& Twikromo, 2017). Begitu pula dengan Bandung, kota kembang ini telah diakui memiliki kemajuan di bidang pendidikan (Tarigan et al, 2016). Tidak mengherankan jika baik Yogyakarta maupun Bandung memiliki daya tarik kaum muda untuk melanjutkan pendidikan yang lebih tinggi. Ketika bermigrasi ke Yogyakarta dan Bandung, kaum muda akan menghadapi tantangan untuk menyesuaikan diri dengan lingkungan baru.

Pendatang diharapkan mampu beradaptasi dengan lingkungan baru, baik secara emosional maupun sosial. Apabila pendatang tidak mampu beradaptasi dengan lingkungan baru, maka pendatang akan mengalami kegagalan selama proses adaptasi. Kegagalan proses adaptasi secara sosial menyebabkan individu mengalami isolasi dengan lingkungan sosial (Y. Y. Kim, 2001), individu juga akan mengalami dampak secara psikologis seperti merasa stres, merasa tertekan (Alemi \& Stempel, 2018), gegar budara (culture shock) (Wang et al., 2018), perasaan tidak menyenangkan, dan merasa cemas (Unjore, 2014). Selanjutnya, budaya, bahasa, dan gaya komunikasi yang berbeda secara fisik juga dapat menghambat proses adaptasi para pendatang (Muchura-Theuri \& Obuya, 2018).

Kegagalan dalam beradaptasi dengan budaya baru akan memicu kesulitan secara psikologis, fisik atau perilaku, dan kesalahpahaman (Rozaimie, 2019). Menurut Kim (2001) kegagalan proses adaptasi menyebabkan pendatang mengalami dekulturasi, pendatang cenderung menolak dan menghindari interaksi dengan budaya setempat. Sebaliknya, jika pendatang mengambil nilai budaya setempat dengan mencoba berinteraksi dan berkomunikasi dengan lingkungan budaya setempat, maka pendatang mengalami proses akulturasi.

Proses adaptasi juga dapat menyebabkan dekulturasi dengan beberapa budaya asli dan akulturasi terhadap budaya baru. Apabila individu mengalami perubahan secara psikologis, sosial, dan budaya dengan lingkungan budaya baru, berarti individu tersebut sudah mencapai tahap asimilasi. Proses adaptasi juga dipengaruhi oleh kemampuan individu dalam berkomunikasi dengan masyarakat setempat, adaptasi dengan lingkungan budaya baru, dan 
juga faktor predisposisi yang ada pada individu (Y. Y. Kim, 2017).

Beberapa penelitian sebelumnya memiliki perbedaan konteks dengan penelitian yang telah dilakukan peneliti di kota Yogyakarta dan Bandung. Penelitian Arbabi et al. (2017) melakukan eksplorasi masalah transisi lintas budaya pada remaja Iran yang bermigrasi ke negara Malaysia. Titzmann dan Fuligni (2015) melakukan penelitian proses adaptasi pendatang yang melakukan migrasi internasional dan menekankan pentingnya proses akulturasi. Ariza (2010) meneliti perkembangan generasi kedua kaum muda Puerto Rico yang bermigrasi selama berada di Orlando dengan konteks kota metropolitan. Kim (2017) dengan penelitiannya yang berfokus pada eksplorasi adaptasi pada imigran, pengungsi, dan pendatang sementara yang ada di negara Amerika Serikat dan Eropa.

Migrasi yang dilakukan pada kaum muda di kota Yogyakarta dan Bandung merupakan migrasi internal (migrasi interregional) yang sangat berbeda dengan proses migrasi dan adaptasi yang telah dilakukan pada penelitian terdahulu. Oleh karena itu penelitian ini dimaksudkan untuk mengeksplorasi proses adaptasi kaum muda yang sedang menempuh pendidikan di kota Yogyakarta dan Bandung.

Penelitian ini dilakukan dengan perspektif psikologi ulayat (indigenous psychology). Menurut berbagai ahli, penelitian ini dapat digunakan untuk memahami perilaku dan proses berpikir manusia pribumi (indigenous) yang ada di wilayah atau kultur budaya tertentu dan tidak diambil dari wilayah atau kultur budaya lain, serta menggunakan desain masyarakat dari daerah atau kultur budaya tersebut (Berry \& Kim, 1993; Faturochman. et al,, 2017; U. Kim et al., 2006). Penelitian psikologi ulayat sangat penting dilakukan dan diterapkan agar dapat membantu mengembangkan penelitian psikologi yang peka terhadap variasi budaya yang ada pada setiap masyarakat. Penelitian psikologi ulayat juga sangat penting dilakukan untuk mengurangi dominasi universalitas perspektif psikologi barat (Berry, 2015).

Penelitian ini bertujuan untuk mengeksplorasi adaptasi pada kaum muda yang bermigrasi ke kota Yogyakarta dan Bandung dengan perspektif psikologi ulayat. Hal ini menawarkan keterbaruan dari sisi perspektif dan konteks penelitian. Kaum muda yang bermigrasi adalah mahasiswa yang sedang menempuh pendidikan di perguruan tinggi. Peneliti ingin mengetahui bagaimana proses adaptasi pada kaum muda yang bermigrasi ke kota Yogyakarta dan Bandung. Peneliti juga mengeksplorasi bagaimana proses adaptasi dapat memengaruhi emosi negatif, adanya hambatan selama proses adaptasi, dan cara mengatasi hambatan yang dirasakan kaum muda selama melakukan proses adaptasi.

\section{Metode}

Penelitian ini menggunakan pendekatan psikologi ulayat untuk mengeksplorasi 
pengalaman adaptasi kaum muda yang bermigrasi ke kota Yogyakarta dan Bandung. Penelitian ini menggunakan analisis tematik yang bertujuan untuk mengidentifikasi polapola atau tema-tema adaptasi. Tahapan yang dilakukan adalah mencoba memahami transkrip wawancara, melakukan proses pengkodean awal, mencari tema, mengulas tema, dan menjelaskan tema (Maguire \& Delahunt, 2017).

Partisipan dalam penelitian ini adalah 118 mahasiswa yang sedang menempuh pendidikan di Yogyakarta (30 laki-laki dan 88 perempuan) dan 82 mahasiswa di Bandung (30 laki-laki dan 52 perempuan). Partisipan ditentukan dengan kriteria (a) sedang menempuh pendidikan S1 di perguruan tinggi, (b) rentang usia 16 - 24 tahun, dan (c) mahasiswa pendatang yang berasal dari luar kota Yogyakarta maupun kota Bandung. Penelitian dilakukan pada mahasiswa yang sedang menempuh pendidikan di kota Yogyakarta dan Bandung, karena kedua kota ini memiliki kualitas pendidikan yang sangat baik di Indonesia (Kemenristekdikti, 2018), sehingga mendorong banyak kaum muda untuk bermigrasi ke kota ini.

Penelitian ini menggunakan kuesioner dengan pertanyaan terbuka (open-ended questionnaire) dan Diskusi Kelompok Terarah/ DKT (Focused Group Discussion/FGD) untuk mendapatkan gambaran umum secara terbuka mengenai pengalaman kaum muda saat beradaptasi. Penyebaran kuesioner dengan pertanyaan terbuka dilakukan kepada partisipan yang sesuai dengan kriteria secara daring. Kuesioner dengan pertanyaan terbuka digunakan dengan pertanyaan utama "Ceritakan bagaimana pengalaman anda dalam melakukan proses adaptasi di kota ini". Setelah mengeksplorasi dengan menggunakan pertanyaan terbuka, peneliti menyeleksi partisipan untuk mengikuti DKT berdasarkan respon kuesioner dengan pertanyaan terbuka tersebut. Peneliti melakukan DKT kepada partisipan yang menyatakan kesediaannya, agar peneliti dapat mengeksplorasi emosi dan menggali hambatan psikologis serta hambatan sosial yang ditimbulkan karena adanya perbedaan kebiasaan atau budaya. Jumlah partisipan yang mengikuti DKT adalah 28 partisipan, sebanyak 13 partisipan mengikuti DKT di kota Yogyakarta dan 15 partisipan di kota Bandung.

Peneliti menggunakan aplikasi MAXQDA Pro 12 untuk membantu proses coding dan analisis. Selanjutnya, peneliti melakukan pengecekan ulang pada data yang telah diperoleh untuk menjaga kredibilitas hasil penelitian. Pengecekan ulang terhadap tema dapat dilakukan oleh peneliti sebagai bahan pertimbangan terhadap tema-tema yang terkesan janggal dan tidak seharusnya muncul (Herdiansyah, 2015).

\section{Hasil}

Terdapat lima tema yang diperoleh dari data pertanyaan terbuka dan juga DKT pada 
kaum muda yang ada di kota Yogyakarta maupun kota Bandung. Tema-tema itu digambarkan dengan uraian seperti berikut.

\section{Mencari informasi}

Kaum muda di kota Yogyakarta melakukan proses adaptasi dengan mencari informasi melalui beberapa cara seperti: (1) Melakukan evaluasi dengan belajar dari kesalahan saat memilah budaya yang akan diterapkan ketika beradaptasi; (2) Memahami kebiasaan dan budaya yang dilakukan dengan cara memahami karakter teman sebaya, memahami kebiasaan dengan bertanya kepada orang yang ada di lingkungan setempat, dan memahami bahasa lokal; (3) Memahami lingkungan kota, tempat tinggal, dan kampus dengan bertanya, membuat peta lingkungan, dan menganalisa situasi terlebih dahulu; dan (4) Mengenali lingkungan di sekitar tempat tinggal. Selama proses adaptasi berlangsung, kaum muda juga memanfaatkan media sosial dan informasi kampus. Media sosial yang digunakan itu seperti Instagram, Twitter, Whatsapp dan Line.

\section{Tabel 1}

Tema Mencari Informasi

Subtema Partisipan

Melakukan evaluasi dengan belajar "Saya pelajari dari kesalahan. Contohnya budaya yang aneh buat dari kesalahan orang Jogja, ga saya terapkan lagi. Lainnya hampir sama" (R, etnis Sunda)

Memahami kebiasaan dan budaya (karakter, kebiasaan, dan bahasa lokal)

"Berusaha untuk memahami karakter-karakter teman saya yang berasal dari daerah berbeda termasuk yang asli Yogyakarta" (S, etnis Gayo)

"Mempelajari sifat-sifat orang Bandung asli, pada awalnya saya tidak terlalu banyak omong dengan orang-orang biar kenal dulu kebiasaan dan cara ngobrolnya bagaimana" (C, etnis Batak)

"Sikap pun juga harus diubah agar bisa bergaul dengan teman-teman di Bandung" (C, etnis Minangkabau)

"Mungkin saya akan bertanya ke beberapa orang terdekat seperti ibu kos, teman kos mengenai tata cara berperilaku dan adat sopan santun" ( $\mathrm{T}$, etnis Minangkabau)

"Penyesuaian cara bicara yang medok dari Jawa" (P, etnis Jawa)

Memahami lingkungan (kota, "Bertanya tentang daerah Jogja" (R, etnis Jawa)

tempat tinggal, dan kampus)

"Sesimpel mencoba mengenal tetangga sekitar dan mentally bikin peta lingkungan dengan berjalan-jalan di area kos dan kampus" (F, etnis Sunda)

"Di lingkungan kampus: Awalnya menganalisa situasi sekitar kampus terlebih dahulu" (D, etnis Jawa)

Mengenali lingkungan

"Pertama kenali dengan lingkungan di sekitar tempat tinggal" (I, etnis Jawa).

Catatan. Pengambilan data dilakukan pada Maret 2019. 


\section{Berinteraksi}

Kaum muda di kota Yogyakarta mencoba berusaha untuk berinteraksi dengan membangun relasi melalui cara berinteraksi dengan lingkungan masyarakat, mengikuti suatu kegiatan, dan berinteraksi dengan teman.
Selain itu, mahasiswa di kota Bandung juga melakukan adaptasi dengan membangun relasi dengan teman agar dapat lebih mengenal budaya dan kebiasaan warga di kota tersebut dan berinteraksi dengan masyarakat mengenai lingkungan sekitar tempat tinggal.

\section{Tabel 2}

\section{Tema Berinteraksi}

\begin{tabular}{ll}
\hline \multicolumn{1}{c}{ Subtema } & \multicolumn{1}{c}{ Partisipan } \\
\hline Berinteraksi dengan & "Mungkin saya akan bertanya ke beberapa orang terdekat seperti ibu \\
lingkungan masyarakat & kos" (W, etnis Minangkabau) \\
& "Banyak berkomunikasi juga dengan masyarakat lokalnya, biasanya \\
& tanya jawab mengenai lingkungan sekitar tempat tinggal” (V, etnis \\
& Tionghoa) \\
"Mencari komunitas agar lebih cepat beradaptasi” (Y, etnis Sangihe) & \\
Mengikuti kegiatan & "Mencari teman yang pas dan nyaman" (F, etnis Sunda) \\
"Berteman dengan orang Bandung asli untuk lebih mengenal budaya \\
dan kebiasaan warga Bandung” (P, etnis Betawi)
\end{tabular}

\section{Menyesuaikan diri}

Setelah melakukan pencarian informasi dan juga membangun relasi melalui interaksi, kaum muda yang ada di kota Yogyakarta mulai mencoba menyesuaikan diri dengan kondisi kota, belajar bersikap ramah, menyesuaikan kebiasaan, serta belajar untuk hidup mandiri. Hampir sama dengan kaum muda di kota Yogyakarta, hanya saja kaum muda di kota Bandung justru menyesuaikan diri dengan belajar hidup mandiri, mengikuti kebiasaan terhadap norma, budaya, transportasi, proses belajar, dan relasi. 
Tabel 3

Tema Menyesuaikan Diri

\begin{tabular}{|c|c|}
\hline Subtema & Partisipan \\
\hline $\begin{array}{l}\text { Menyesuaikan diri } \\
\text { dengan kondisi kota }\end{array}$ & $\begin{array}{l}\text { "Mencoba beradaptasi dengan iklim/cuaca yang biasanya berbeda dari daerah asal" } \\
(\mathrm{P}, \text { etnis Toraja) }\end{array}$ \\
\hline $\begin{array}{l}\text { Belajar bersikap } \\
\text { ramah }\end{array}$ & $\begin{array}{l}\text { "Kita harus ramah dan baik, agar lingkungan sekitar juga bisa menerima kita } \\
\text { dengan baik" (N, etnis Jawa) }\end{array}$ \\
\hline \multirow{3}{*}{$\begin{array}{l}\text { Menyesuaikan } \\
\text { kebiasaan }\end{array}$} & "Memperhatikan kebiasaan orang-orang sini" (Y, etnis Sunda) \\
\hline & $\begin{array}{l}\text { "Belajar beradaptasi dengan perbedaan kondisi sekolah dengan perkuliahan, baik itu } \\
\text { metode belajar, guru atau dosen, teman dan lingkungan lainnya" (M, etnis Melayu) }\end{array}$ \\
\hline & $\begin{array}{l}\text { "Mengikuti arus pergaulan, ikuti dan pahami, adaptasi, lalu cari lingkungan yang baru } \\
\text { lagi" (M, etnis Jawa) }\end{array}$ \\
\hline \multirow[t]{2}{*}{ Belajar mandiri } & $\begin{array}{l}\text { "Awalnya masih suka dianter saudara, suatu hari ada kakak perempuan saya tapi ia } \\
\text { tidak menjemput saya yang akhirnya disuruh untuk naik angkot dan dikasih tau } \\
\text { jurusannya dari kampus ke kosan saudara saya lalu dari sana saya memberanikan dir } \\
\text { hingga berani naik angkot." (T, etnis Sunda). }\end{array}$ \\
\hline & $\begin{array}{l}\text { "Mungkin adaptasi yang saya lakukan, itu adaptasi untuk diri sendiri. Lebih ke mandirl } \\
\text { hidup sendiri. Kayak gimana tuh proses adaptasi hidup sendiri? Sebenarnya sih } \\
\text { adaptasi hidup sendiri bukan dari saya langsung di Jogja, saya kan dari Semarang ke } \\
\text { Purworejo itu saya sendiri gak sama orang tua saya" (Z, etnis Jawa) }\end{array}$ \\
\hline
\end{tabular}

Catatan. Pengambilan data dilakukan Maret 2019.

\section{Faktor penghambat adaptasi}

Selama proses adaptasi berlangsung, tentu ada kemungkinan proses tersebut tak berjalan mulus sesuai dengan yang diharapkan kaum muda selama melakukan migrasi. Kaum muda yang bermigrasi ke kota Yogyakarta juga dapat mengalami berbagai hambatan dalam melakukan proses adaptasi. Hambatan yang dirasakan selama proses adaptasi itu seperti mengalami kebingungan, hambatan relasi, adanya perasaan cemas dan takut, serta kesulitan dalam menjalani proses adaptasi. Selain itu kaum muda yang bermigrasi ke kota Yogyakarta juga mengalami kendala adaptasi terhadap manajemen keuangan, makanan, bahasa, relasi, dan kebiasaan yang ada.

Berbeda dengan kaum muda yang bermigrasi ke kota Yogyakarta, di kota Bandung, kaum muda merasakan ketidaknyamanan selama proses adaptasi yaitu merasa kesepian dan tidak nyaman, merasa tertekan, serta merasa cemas, merasa tidak senang, merindukan rumah, merasa bingung, merasa stres, penyesuaian terhadaplingkungan, penyesuaian proses belajar, dan penyesuaian relasi. Selain itu kaum muda yang ada di kota Bandung juga memberikan gambaran mengenai hambatan yang dirasakan seperti kurangnya informasi manajemen diri, transportasi, kebiasaan, relasi, dan bahasa. Kaum muda yang ada di kota Bandung juga mempunyai cara untuk mengatasi hambatan yang dirasakan saat beradaptasi melalui beberapa cara, yaitu mengembangkan pemikiran yang positif, berusaha mencari dukungan, dan juga melakukan pengalihan atas masalah yang dirasakan. 


\section{Tabel 4}

Tema Faktor Penghambat Adaptasi

\begin{tabular}{ll}
\hline Subtema & \multicolumn{1}{c}{ Partisipan } \\
\hline Mengalami & "Budaya sungkan bikin bingung" (D, etnis Rote) \\
kebingungan & "Bingung sih, kan kota Bandung ini merupakan tempat daerah yang baru dalam diri \\
& saya ini. Kalau budaya Bandung ini kan berbeda dengan budaya daerah asal aku \\
& ini" (N, etnis Jawa) \\
& "Tidak sulit bagi saya untuk berteman dengan orang baru jika orang tersebut yang
\end{tabular}

Hambatan relasi "Tidak sulit bagi saya untuk berteman dengan orang baru jika orang tersebut yang memulai mengajak saya bicara, bercanda. Jika orang lain hanya diam dan kurang berinteraksi dengan saya (pendiam/menghindar), saya merasa bahwa saya tidak harus akrab dengan dia" (N, etnis Bugis)

Kesulitan dalam "Awal-awal saya tinggal di Jogja saya sangat tidak betah, setiap hari menangis dan menjalani telpon orang tua" (K, etnis Jawa)

proses adaptasi. Jadi karena sebenernya dari SMA tuh orangnya ga betah belajar lama-lama. Kalau di SMA kan di terangin nya jelas kan, buku disediain. Nah di kuliah ini jadi sedikit kaget gitu lah, buku nyari sendiri, terus dosennya ya gitu lah ngejelasinnya kurang terlalu mendalam jadi kita tuh harus belajar sendiri” (L, etnis Sunda)

"Cuman ya agak sulit itu proses adaptasi terhadap diri sendiri, kemandirian diri sendiri. Karena waktu itu pertama kali ke Bandung itu pertama kali nge-kos. Jadi ya proses sama diri sendiri" (A ,etnis Sunda)

Manajemen keuangan

Makanan

Bahasa

Relasi

Kebiasaan
"Terus sama manage keuangan, kan kalo di sini untuk cewek kan banyak brandbrand yang pokoknya kalo dapat kiriman itu dulu deh. Akhir bulannya belakangan" (A, etnis Bantik)

"Kalo makanan, aku suka kuliner, semua makanan ku coba. Aku jujur gak pernah makan salad buah, ditawarin temenku aku mau muntah. Tapi ya gak pa pa. Kalo makanan manis dah biasa. Aku coba masakan Padang, aku merasa mending bikin di rumah. Makanan Jawa yang ga bisa makan yaitu rolade, kenyel. Kalo manajemen keuangan udah biasa sama nenek, nyuci sendiri, masak sendiri, nyari makan sendiri, kadang coba kerja" (0, etnis Minangkabau)

"Proses adaptasi di Bandung, satu tentang makanan sama jadi kalau di Kendari Sulawesi, orang rata-rata makan ikan ya pak, pas saya sampe di sini makan ayam terus. Terus beda ayam potong beda ayam kampung kan pak. Di sini kan ayam potong jadi semakin hari semakin enek, kangen ikan gitu. Tapi pas saya makan ikan di sini ternyata harganya mahal dan rasa nya ga sama, mungkin makanan paling rese" (C etnis Tolaki, Maret 2019)

"Semuanya berjalan cukup baik, kecuali bahasa" (A, etnis Sunda)

"Kalau dari segi bahasa bingung juga soalnya ga ngerti sama sekali” (L, etnis Bugis)

"Awalnya sangat sulitya kang soalnya kan beda jauh banget dari Sumatera ke Jawa khususnya Sunda gitu, dari kosakatanya juga lebih banyak di Sunda gitu, di Sumatra kan khususnya Jambi ga terlalu banyak kosakata. Tapi kebetulan dari awal PPMB di univ. ketemu sama temen yang migrasi juga, jadi dia ga terlalu ngegunain bahasa Sunda, bisa nyeimbangin juga" (S, etnis Melayu)

"Aku harus berhati-hati berkata-kata lagi karena secara intonasi mereka udah nganggap aku kasar. Padahal aku tu gak ngegas. Aku tuh seperti ini please" (F, etnis Sunda)

"Tapi yang aku gak bisa tu akulturasi di sini. Di sini budaya Islamnya lebih kuat ya. Kan aku dari lingkungan yang walaupun bercampur banyak, orang kalau menyapa itu yang netral dengan "selamat pagi, selamat siang". Di sini orang ngomongnya 


\section{Faktor pendukung adaptasi}

Selama bermigrasi, kaum muda juga terbantu selama proses adaptasi karena adanya faktor-faktor pendukung selama menjalani proses adaptasi di kota Yogyakarta dan Bandung. Faktor-faktor pendukung tersebut mencakup beberapa hal, seperti sudah terbiasa hidup sendiri dan adanya edukasi yang diberikan oleh lingkungan sekitar selama bermigrasi ke kota Yogyakarta. Berbeda dengan kota Yogyakarta, di kota Bandung faktor pendukung untuk beradaptasi disebabkan karena adanya kesamaan kultur budaya dan banyaknya teman perantauan atau pendatang.

\section{Tabel 5}

Tema Faktor Pendukung Adaptasi

\begin{tabular}{l} 
Subtema \\
\hline Terbiasa hidup sendiri \\
Edukasi yang diberikan \\
oleh lingkungan sekitar \\
perantauan mengenai \\
budaya
\end{tabular}

Mengembangkan pemikiran positif

Berusaha mencari cara penyelesaian

Mencari dukungan (support)
Partisipan

"Gak ada nangis? Gak.. gak ada nangis, paling kangen aja. Kalo diri sendiri sih nggak. Nggak ada masalah sih, kan udah kebiasa dari Malang juga, kan saya anak pertama, cenderung kalo kemana-mana yaudah kalo kemana-mana sendiri atau sama temen. Terbiasa udah gitu" (D, etnis Jawa).

"Ibu kos aku itu orang Jogja asli, waktu pertama kali ke sini tu beliau udah ngajarin bahwa 'Ibu tu mohon sama kalian, ketemu Ibu disapa.' Ternyata budayanya kaya gitu ya, di luar kos kalo kenal atau gak kenal ternyata emang saling sapa, senyum dan bilang kulonuwun atau permisi lah intinya. Dari situ aku udah jalanin dan tanya ke temen-temen yang Jogja, 'ternyata Jogja gini ya'”' (I, etnis Minangkabau).

"Ada cara ngatasinnya saya ikut beberapa kepanitiaan dan alhasil saya ngambil danus ya pak malah dari danus itu muncul lagi nih stres untuk menutupi yang ga kejual, jadi stres nya double. Terus saya mikir lagi ya udahlah gapapa mending saya stres gara-gara danus daripada pengen pulang terus gitu, soalnya kalau stres gara-gara danus tuh malah jadi semangat saya buat ke kampus buat jualan. Daripada saya stres homesick saya pengennya pulang, males ke kampus" (W, etnis Jawa).

"Saya mengatasinya beli Bon Cabe. Atau engga minta pedes banget gitu ke abang-abangnya, itu doang sih" (M, etnis Rejang).

"Terus waktu itu karena mungkin di Bandung masih ada bawaan itu, jadinya kuliahnya ga fokus, jadi kayak masih mikirin yang masa lalu kemaren gitu. Terus kesini-kesini mungkin kakak saya ngeliat perubahan saya, jadi dinasihatin gitu kalau saya mikir yang itu terus ga akan mungkin jadi lebih baik, semenjak dinasihatin kayak lebih ikhlas sama keadaan yang ada, sama lebih mendekatkan diri sama Allah" (R, etnis Sunda).

“Diskusi sama teman saat di perkuliahan" (H, etnis Minangkabau).

"Jadi biasanya juga kalau ngatasin lebih ngomong cerita ke mama saya, nanti mama saya yang kasih tau kau harusnya seperti ini, gini. Yaudah ntar saya ikutin mama saya ntar dicoba sendiri. Iya, telpon tanya biasanya apapun kata mama lebih bener ya. Biasanya sih kayak saya harus ngapain, yang paling sering saya tanyain kalau saya sakit. Saya gimana ini mau ke dokter gitu, saya harus gimana, saya bilang ke mama nanti mama kasih tau ya kamu kalau mau kayak gini harus cari yang terdekat" (Y, etnis Tionghoa). 


\begin{tabular}{ll}
\hline \multicolumn{1}{c}{ Subtema } & \multicolumn{1}{c}{ Partisipan } \\
\hline Melakukan pengalihan atas & "Intinya sih kalau saya mengatasinya musik atau engga jalan-jalan \\
masalah yang dirasakan. & dulu aja sementara langsung balik ngerjain lagi" (B, etnis Sunda). \\
Kesamaan kultur budaya & "Terus kalau budaya mah kan saya juga orang Sunda gitu, jadi ga \\
& terlalu susah gitu. Soalnya kan kalau di Bandung mah campur-campur, \\
& jadi kadang ada yang ngomong Sunda gitu, ada juga yang ngomong \\
& Indonesia. Jadi saya juga udah terbiasa gitu waktu SMA jadinya \\
& ngomong Sunda sama Indonesia tuh ga terlalu sulit lah udah terbiasa \\
& kalau masalah budaya, cara ngomongnya mah. Paling yang rada ini \\
& nya mah mungkin kayak udah sih itu aja hehe" (I, etnis Sunda). \\
Banyak teman perantauan & "Tapi kebetulan dari awal PPMB di univ ketemu sama temen yang \\
atau pendatang & migrasi juga, jadi dia ga terlalu ngegunain bahasa Sunda, bisa \\
& nyeimbangin juga. Terus pas di kelas juga kebetulan teman pertama \\
& kenalnya juga migrasi juga, jadi sama-sama saling mengimbangi, \\
& sama-sama dari daerah luar. Terus di kelas juga kebanyakan dari \\
& migrasi, dan jauh-jauh. Ada yang dari Batam, Riau, Medan, Makassar \\
& juga ada. Jadi di kelas itu alhamdulillahnya udah saling open gitu, jadi \\
& apapun perbedaannya saling ngimbangin" (S, etnis Melayu).
\end{tabular}

\section{Pembahasan}

Penelitian ini bertujuan untuk menggali proses adaptasi pada kaum muda yang bermigrasi ke kota Yogyakarta dan Bandung. Penelitian ini menghasilkan temuan tiga tema proses adaptasi dan dua faktor predisposisi yang memengaruhi proses adaptasi yang dilakukan kaum muda saat bermigrasi ke kota Yogyakarta dan Bandung. Tiga tema proses adaptasi ini yaitu mencari informasi, berinteraksi, dan menyesuaikan diri. Selama kaum muda bermigrasi, terdapat pula dua faktor predisposisi yang memengaruhi proses adaptasi kaum muda. Dua faktor predisposisi itu terdiri dari faktor penghambat dan faktor pendukung kaum muda selama beradaptasi di kota Yogyakarta dan Bandung.

Kaum muda yang ada di kota Yogyakarta dan Bandung menghadapi suatu tantangan saat bermigrasi karena adanya hambatan- hambatan yang dirasakan selama beradaptasi. Hambatan yang dirasakan kaum muda selama beradaptasi mencakup beberapa hal, seperti mengalami kebingungan, hambatan relasi, perasaan cemas dan takut, serta kesulitan dalam menjalani proses adaptasi, serta masalah manajemen diri, manajemen keuangan, makanan, bahasa, dan kebiasaan. Kaum muda di kota Yogyakarta dan Bandung juga berusaha untuk mengatasi ketidakmampuan beradaptasi dengan mengelola perasaan frustasi agar tidak mengalami isolasi, baik secara emosional maupun sosial.

Hambatan yang dirasakan kaum muda selama beradaptasi menjadi lebih berkurang karena kaum muda berusaha untuk mencari cara untuk mengatasi hambatan yang dirasakan dengan mengembangkan pemikiran positif, berusaha mencari cara penyelesaian, mencari dukungan, dan juga melakukan 
pengalihan atas masalah yang dirasakan. Berdasarkan uraian di atas, menurut Aldasheva (2014), setiap individu akan mencari suatu cara dalam menghadapi suatu tantangan saat beradaptasi, baik secara psikologis maupun yang termanifestasi melalui perilaku.

Adanya faktor pendukung yang memengaruhi proses adaptasi selama bermigrasi juga dapat mengurangi hambatanhambatan kaum muda di kota Yogyakarta dan Bandung selama proses adaptasi. Faktor-faktor pendukung itu meliputi terbiasa hidup sendiri, edukasi mengenai budaya dari lingkungan sekitar, kesamaan kultur budaya, dan banyak berteman dengan pendatang. Faktor-faktor pendukung di atas berkaitan juga dengan hasil penelitian Wu (2017) yang menjelaskan pentingnya modal sosial seperti keluarga, teman sebaya, dan masyarakat terhadap proses psikososial seorang pendatang. Modal sosial akan berdampak positif terhadap kesehatan mental individu, sehingga individu dapat memiliki harga diri yang tinggi, mengurangi depresi dan rasa permusuhan, dan meningkatnya kepuasan hidup.

Faktor penghambat dan faktor pendukung yang telah diuraikan di atas, dapat memengaruhi proses adaptasi yang dijalani oleh kaum muda selama bermigrasi. Kaum muda di kota Yogyakarta dan Bandung berusaha untuk mencari informasi, berinteraksi, dan menyesuaikan diri saat bermigrasi. Setiap etnis juga memiliki perbedaan dalam menjalani proses adaptasi selama bermigrasi di kota Yogyakarta dan Bandung. Etnis yang berasal dari luar pulau Jawa (Melayu, Minangkabau, Bugis, Rote, Sangihe, Batak, Rejang, Tolaki, Bantik) berusaha mengurangi hambatan-hambatan selama proses adaptasi dengan cara mencari informasi. Beberapa kaum muda yang berasal dari etnis luar pulau Jawa juga berusaha berinteraksi dan menyesuaikan diri saat bermigrasi ke kota Yogyakarta dan Bandung.

Proses adaptasi kaum muda di kota Yogyakarta dan Bandung juga berkaitan dengan konsep adaptasi yang dijelaskan oleh Kim (2017). Menurutnya, terdapat beberapa konsep adaptasi selama seseorang bermigrasi. Konsep adaptasi itu mencakup proses akulturasi, dekulturasi, dan asimilasi. Akulturasi adalah ketika pendatang mengambil nilai budaya setempat dengan mencoba berinteraksi dan berkomunikasi dengan orang dari budaya setempat. Berbeda dengan akulturasi, dekulturasi terjadi ketika pendatang cenderung menolak dan menghindari interaksi budaya setempat. Namun begitu, jika pendatang bisa berkomunikasi dan berinteraksi dengan caracara budaya lokal, berarti ia berada pada proses adaptasi yang tertinggi, yaitu asimilasi.

Selama melakukan proses adaptasi, kaum muda yang berasal dari pulau Jawa cenderung mengalami proses asimilasi saat mereka berada di kota Yogyakarta dan Bandung. Asimilasi itu terjadi karena kaum muda masih memiliki kesamaan budaya dengan kota Yogyakarta maupun Bandung, 
sehingga mereka lebih mudah untuk berinteraksi dan menyesuaikan diri dengan baik di kota tersebut. Kaum muda yang berasal dari luar pulau Jawa tidak mengalami proses asimilasi, namun mereka mengalami proses akulturasi saat melakukan proses adaptasi. Sebagian dari kaum muda juga mengalami kesulitan saat beradaptasi, sehingga tetap merasa tidak nyaman atau stres dan bahkan mengalami konflik. Hal tersebut umumnya dialami oleh kaum muda yang mengalami dekulturasi.

Keterbatasan penelitian ini adalah proporsi yang tidak seimbang antara laki-laki dan wanita di kedua kota. Hal ini memengaruhi hasil gambaran proses adaptasi yang ditemukan antara laki-laki dan wanita yang belum sepenuhnya representatif mewakili fenomena di lapangan. Selain itu, proporsi partisipan lebih didominasi oleh kaum muda yang berasal dari pulau Jawa yang cenderung dekat dengan kota migrasi. Konteks kedekatan budaya dari asal subjek ini dapat memengaruhi proses adaptasi karena adanya sosiokultural familier dibandingkan dengan daerah asal yang jaraknya lebih jauh.

\section{Simpulan}

Hasil penelitian ini telah menjawab tujuan penelitian. Selama bermigrasi, kaum muda melakukan proses adaptasi dengan mencari informasi, berinteraksi, dan menyesuaikan diri. Proses adaptasi kaum muda juga dipengaruhi oleh adanya dua faktor predisposisi, yaitu faktor penghambat dan faktor pendukung selama beradaptasi. Penelitian ini diharapkan dapat membantu kaum muda dengan pengalaman awal bermigrasi ke kota besar melalui pengetahuan mengenai proses adaptasi di kota besar.

\section{Saran}

Penelitian dengan topik yang serupa masih diperlukan. Penelitian selanjutnya dapat mempertimbangkan proporsi jenis kelamin yang lebih setara antara laki-laki dan perempuan sehingga diharapkan dapat lebih mewakili pengalaman adaptasi kaum muda yang bermigrasi. Penelitian berikutnya juga dapat mempertimbangkan variasi daerah asal partisipan yang lebih beragam.

\section{Referensi}

Aldasheva, A. A. (2014). Individual adaptation strategies. Human Psychology, 40(6), 597-602. https://doi.org/10.1134/ S0362119714060024

Alemi, Q., \& Stempel, C. (2018). Discrimination and stress among Afghan refugees in northern California: The moderating role of pre and post migration factors. Plos One, 13(5), e0196822. https://doi.org/ 10.1371/journal.pone.0196822

Arbabi, K., Yeh, C. J., Mahmud, Z., \& Salleh, A. (2017). From monocultural to multicultural: Adaptation of iranian immigrant adolescents in Malaysia. Journal of Adolescent Research, 32(3), 371-402. https://doi.org/10.1177/ 0743558416630811

Ariza, D. (2010). Puerto Rican youth in Central Florida: Adaptation and identity. Centro Journal, 22(1), 129-153. https://doi.org/ 10.1177/0022022119835979 
Berry, J. W. (2015). Global psychology: implications for cross-cultural research and management. Cross Cultural Management, 22(3), 342-355. https:// doi.org/10.1108/CCM-03-2015-0031

Berry, J. W., \& Kim, U. (1993). The way ahead: From indigenous psychologies to a universal psychology. In U. Kim \& J. W. Berry (Eds.), Cross-cultural research and methodology series, Vol. 17. Indigenous psychologies: Research and experience in cultural context (pp. 277-280). SAGE Publications, Inc.

Faturochman, Minza, W. M., \& Nurjaman, T. A. (Eds.). (2017). Memahami dan mengembangkan indigenous psychology. Pustaka Pelajar.

Herdiansyah, H. (2015). Metodologi penelitian kualitatif untuk ilmu psikologi. Salemba Humanika.

Jong, E. D., \& Twikromo, A. (2017). Friction within harmony: Everyday dynamics and the negotiation of diversity in Yogyakarta, Indonesia. Journal of Southeast Asian Studies, 48(1), 71-90. https://doi.org/https://doi.org/ $10.1017 /$ S0022463416000485

Kemenristekdikti. (2018). Umumkan peringkat 100 besar perguruan tinggi Indonesia non vokasi Tahun 2018. Kemenristekdikti.Go.Id. https:// ris te kdikt i.go.id/kabar / kemenristekdikti-umumkan-peringkat100-besar-perguruan-tinggi-indonesianon-vokasi-tahun-2018/

Kim, U., Yang, K., \& Hwang, K. (2006). Contributions to indigenous and cultural psychology: Understanding people in context. In Indigenous and cultural psychology: Understanding people in context (pp. 3-25). Springer. https:// doi.org/10.1007/0-387-28662-4_1

Kim, Y. Y. (2001). Becoming intercultural: An integrative theory of communication and cross-cultural adaptation. SAGE Publications, Inc. https://doi.org/http:/ /dx.doi.org/10.4135/9781452233253
Kim, Y. Y. (2017). Cross-cultural adaptation. In Y. Y. Kim (Ed.), Oxford Research Encyclopedia of Communication. University Press. https://doi.org/ 10.1093 / a c r e f o r e / 9780190228613.013.21.

Maguire, M., \& Delahunt, B. (2017). Doing a thematic analysis: A practical, step-bystep guide for learning and teaching scholars. All Ireland Journal of Higher Education, 9(3), 3351-33514. https:// ojs.aishe.org/index.php/aishe-j/article/ view/335

Malamassam, M. A. (2016). Youth migration in Indonesia: Decision to move and choice of destination areas. Indonesian Journal of Geography, 48(1), 65-75. https:// doi.org/10.22146/indo.j.geog,12469

Muchura-Theuri, A. W., \& Obuya, J. (2018). They wouldn't allow me in their conversations. Journal of Intercultural Communication Göteborg, 48.

Rozaimie, A. (2019). Cultural variations and socio-ecocultural understanding on cross-cultural adaptation. Qualitative Report, 23(10), 2538-2551. https:// nsuworks.nova.edu/tqr/vol23/iss10/ $17 /$

Tarigan, A. K. M., Sagala, S., Samsura, D. A., Fiisabiilillah, D. F., Simarmata, H. A., \& Nababan, M. (2016). Bandung City, Indonesia. Cities, 50, 100-110. https:// doi.org/10.1016/j.cities.2015.09.005

Titzmann, P. F., \& Fuligni, A. J. (2015). Immigrants' adaptation to different cultural settings: A contextual perspective on acculturation. International Journal of Psychology, 50(6), 407-412. https://doi.org/10.1002/ ijop.12219

Unjore, S. (2014). Excitement or anxiety? A case study of Indian postgraduate sojourners at University of Nottingham. British Journal of Guidance \& Counselling, 42(5), 557-567. https:// d o i . o r g / 10 . 1080 / 03069885.2014 .933174 
Wang, Y., Li, T., Noltemeyer, A., Wang, A., Zhang, J., \& Shaw, K. (2018). Cross-cultural adaptation of international college students in the United States. Journal of International Students, 8(2), 821-842. https://doi.org/ 10.5281/zenodo.1250383

Wu, Q. (2017). Effects of social capital in multiple contexts on the psychosocial adjustment of Chinese migrant children. Youth \& Society, 49(2), 150-179. https:/ /doi.org/10.1177/0044118X14530133

Received 14 January 2020 Revised 25 February 2020 Accepted 30 May 2020 